\title{
Territorio e identidad en los Andes. Concepciones populares en torno a las zonas ecológicas altas en la sierra de Lima
}

\author{
JUAN JAVIER RIVERA ANDÍA \\ Pontificia Universidad Católica del Perú. Lima
}

\section{RESUMEN}

En las villas campesinas de los Andes encontramos un espacio denominado con términos tales como "alturas", "puna", "jalca" o "pampa". En este territorio se encuentran los pastizales, los roquedales, las pequeñas lagunas, los manantiales y la nieve. Es también el escenario ideal de los amores de juventud y las actividades pastoriles. Finalmente, este territorio es entendido, por los habitantes de las villas, como un espacio de alteridad. Nosotros examinaremos las concepciones andinas acerca de este último aspecto: concepciones concernientes al peligro, la indistinción y la fascinación. Lógicamente, cuando hablamos de alteridad, no podemos dejar de decir, al mismo tiempo, algo acerca de la identidad, de los valores y sentimientos vinculados a ella. Abordaremos el análisis de este espacio de otredad a partir de dos fuentes: las características de los personajes mitológicos asociados a las "alturas" y las connotaciones implícitas del término nativo utilizado para designar este espacio.

Palabras clave: Territorio, Identidad, Andes, Campesinado, Ecología.

\section{SUMMARY}

In Andean villages, there is a space called Alturas, Puna, Jalca or Pampa. This space usually includes rocks, grasslands, meadows, pastures, springs and snow. It is the stage for romance among the youth as well as the roaming of herdsmen. Andean peasants view it as a space of alterity. The author discusses some aspects of this Andean perception: alterity as a dangerous, indistinctive, fascinating place. When one writes about alterity, logically it is impossible not to speak, at the same time, about identity, about the values and feelings linked to such space. The analysis relies on the particularities of the mythological characters associated with it and on the implicit meanings of the native term designating it.

Key words: Territory, Identity, Andes, Peasantry, Ecology.

En los tiempos actuales, muchos antropólogos se han ocupado ya del tema de la "identidad. Se ha discutido mucho sobre cuál es la naturaleza de esta entidad, e incluso sobre la pertinencia de este término para el

$R D T P, \mathrm{LX}, 2$ (2005): 55-76 
estudio de las culturas amerindias. Una de las consideraciones más lúcidas al respecto puede encontrarse en aquellos autores que afirman que la identidad es solo apariencia, que carece de una naturaleza sustantiva y permanente, que se trata de una "cosa" móvil y polimorfa y siempre fluida. Pero lo que más nos interesa resaltar aquí es que, en último término, lo que nosotros somos está constituido por la convergencia de todo aquello que negamos ser. Manuel Gutiérrez Estévez (1993:) ha sintetizado esta perspectiva en los siguientes términos:

Las representaciones del uno y las representaciones de los otros están en continuo proceso de construcción, destrucción y reconstrucción. Su consistencia es siempre precaria y nunca sustancial, aunque todos los implicados, "nosotros" y "ellos", han de pretender que tenga una apariencia de "realidad", de "identidad" propia y ajena. Pero esto no es sino ilusión óptica. Como no hay un "yo" o un "nosotros", tampoco hay un "ellos" o unos "otros" separados, diferenciados por estar en un espacio diferente, por estar al otro lado del espejo. Todos estamos en el mismo espejo. Aunque "ellos" están situados en el margen y de esa posición nace la fuerza de su contra-poder... La identidad, formada por sus representaciones de la alteridad, no es sino el foco virtual de ésta, el lugar donde convergen, refractadas, las imágenes de la alteridad.

Un estudio sobre la identidad o la alteridad no es, pues, sino un estudio de retórica (o, quizá, de óptica). En el caso que nos ocupa aquí se trata de una de las varias retóricas amerindias: la andina.

...el estudio de las representaciones de la identidad y de la alteridad no es, hablando metafóricamente, un estudio de mecánica sino de óptica, de imágenes deformadas, reflejadas o refractadas, de focos virtuales y de emisiones de atributos que se estructuran y re-estructuran de continuo....En la descripción de sus formas, en la morfología de las representaciones de "nosotros" y de "ellos", no hay lugar para una taxonomía clasificatoria; sólo proporciona algún sentido la retórica: los tropos sobre otros mediante los cuales se construye discursivamente la propia identidad.

Entre los variados criterios para analizar los móviles de estas retóricas, el poder — su búsqueda, su rechazo, los intereses creados en torno a él一, ha sido la explicación más común de las representaciones y las estrategias en torno a la alteridad y la identidad se han explicado a menudo en términos políticos (Pérez Galán 2001; Borea 2001a, 2001b). No pretendemos abordar estos problemas aquí. Lo que sí queremos señalar son las características de un elemento recurrente de la retórica de la alteridad en los Andes: un espacio, un territorio que parece condensar distintas ideas de lo "otro". Queremos mostrar qué valoraciones son comúnmente asociadas a este escenario a través del término que ellos usan para referirse a él (ратра) y del lugar que ocupa en la tradición oral andina este territorio. Comencemos por este último. 
1. EXCESIVOS, SILVESTRES Y AJENOS: APUNTES SOBRE ALGUNOS DE LOS PERSONAJES QUE PUEBLAN LAS TIERRAS CIRCUNDANTES A LAS VILLAS ANDINAS

La solemnidad y los tabúes presentes en el ascenso a las alturas parecen obedecer a su concepción como el ámbito privilegiado de los espíritus de los cerros. El wamani, uno de los nombres comunes de estos espíritus, puede "ganarle" o "aprovecharle" el corazón al imprudente: a veces, basta que alguien tropiece o cruce un lugar "malo" para que enferme gravemente y muera: sufriría el kantcha o "señal": cólicos, deposiciones y vómitos sangrantes que conducen a la muerte inmediata (Quispe 1969: 38, 65-66).

Los participantes de las herranzas ayacuchanas invocan, en su peregrinaje del pueblo a la puna, a las divinidades tutelares de los cerros que protegen sus comunidades. Los nombres dados a estos espíritus - como la fuerza de su presencia en las prácticas y discursos de los campesinosvarian según las regiones: wamani (Lucanas. Departamento de Ayacucho), apu o apusuyo (Huamanga. Departamento de Ayacucho), achachila (departamento de Puno), awki (departamento de Cuzco), y auquillo (departamento de Lima). El ganadero y los circunstantes se detienen frente a los pequeños altares construidos a lo largo del camino. Allí, y en la misma estancia donde se ha reunido el ganado, brindan y liban en honor al wamani en el mesa mastay (que pude traducirse por "el tendido de la mesa"). Para protegerse, los hombres usan de varias artimañas: lo rocían todo con un polvillo fino llamado llampu, beben una solución especial llamada ñawin, fuman cigarrillos, consumen el zumo de las hojas de coca y un amasijo picante hecho de la ceniza de ciertas hierbas llamado toqra ${ }^{1}$, todo ello en un número de veces pautado. Estos tres elementos, la coca, la llipta y el cigarrillo son, según los criadores de la sierra de Lima, como resguardos eficientes ante la agresividad del auquillo ${ }^{2}$. En Pacaraos se enfrentaba al auquillo por medio de estrictos ritos:

En esos sitios donde vive el Awkillo es peligroso dejar a las criaturas durmiendo; si se le deja allí le agarra el Awkillo, o sea el susto. La criatura inmediatamente se enferma. Lo curan pagándole al Awkillo. Pagan a las doce de la noche. Van a ese sitio. A la criatura en su cama lo han sobado... con caramelos, galletas, ron, coca;

${ }^{1}$ Según Quispe la tuqra o llipta es una masa preparada de la ceniza del tallo de la quinua (chenopodium quinoa) o del interior del maguey (agave americana).

${ }^{2}$ Adelaar (1982: 22) consigna los términos awki y abuelo para designar los "espíritus de los antepasados": awkim sarishunki, por ejemplo, significa: "El 'abuelo' te agarrarán. En la actualidad, en la sierra del valle del Chancay, predominan dos términos: uno castellano: "abuelo", y otro -derivación castellana del vocablo quechua awki-: "auquillo". 
eso se lleva al sitio donde han dormido las criaturas y se deja todo, con huevo se rompe allí. También lo soban con cuye (cobayo). Todo esto lo dejan allí enterrándolo. A esa hora arman (mastican coca). De ese sitio traen una piedra wankallo [piedra alargada] que significa el espíritu que el Awkillo lo agarró. Lo traen con una tira, la punta con que se amarra a la criatura su vestido al pecho, con eso lo traen amarrado al wankallo ${ }^{3}$. La persona que trae, trae sin voltear para atrás y si la persona voltea para atrás, el espíritu se regresa nuevamente. Entonces no sana la criatura. Van dos hombres para eso. Esos son curiosos, curanderos. (Mendizábal 1964: 96)

Esta es otra narración sobre el enfrentamiento entre los hombres y el espíritu de los cerros:

...se tendió la mesa para el Awkillo, "para él solito, con su coca y su trago"... ofreciéndosele, luego, un cigarrillo encendido, que dejaron en la mesa, en tanto ellos bebían, fumaban y chaqchaban coca [absorbían su jugo manteniéndola en los carrillos] en la otra mesa. El cigarrillo ofrecido al Awkillo se consumió íntegramente, sin apagarse, "echando sus chispas todavía de lo que estaba fumando. Pero no se veía a nadie. Los cigarrillos que fumaban el informante y su tía, sin embargo, se apagaban. La tía dijo... que "el viejo" estaba recibiendo la ofrenda, que estaba contento. Le ofrecieron otro y otro cigarrillo, que también se consumieron. Entonces, la tía le dijo que debía llamar a su hija, con fe... La requirió por el nombre, preguntándole qué era lo que le faltaba, porqué se había quedado allí, qué era lo que deseaba. // A su requerimiento se presentó una avecita blanca. Su tía le dijo que eso no era el alma de la niña, sino la de un adulto. Volvió a llamar a la niña varias veces; apareció entonces una "mariposita blancan. Era el alma de su hija, revoloteó unos instantes y se posó en una rama. Su tía le indicó que debía llevarse una piedra... que era el alma de su hija, que debía envolverla con cuidado, y rápidamente en un pañuelo, y abrigarla bajo su chaqueta y enseguida emprender el regreso, sin volver la cabeza. El no se volvió no obstante que ale parecía" oír voces a sus espaldas. // Al llegar a la casa, su tía, que lo acompañaba, pidió entrar: “¿Comadre, puedo pasar?". La puerta de la casa, donde yacía la enferma al cuidado de su esposo y de su suegra, estaba abierta; ingresaron, depositaron la piedra "bajo su camita" de la niña y su tía procedió a curarla "bañándolan con harina de maíz molido, friccionándola con un cobayo, cigarrillo, caramelos, todo lo cual, después llevó al paraje donde estaba el Awkillo. "Como mi hija era mujercita el viejo se había aficionado. Así dice que se aficiona a las mujeres". (Mendizábal 1964: 97-98).

Esta amenaza de los espíritus de los cerros parece exacerbarse durante los ritos del rodeo. Un elemento observado por nosotros en la comunidad de Vichaycocha, villa del valle de Chancay, parece acercarnos a la respuesta (Rivera Andía 2000, 2003). Los santos patronos de los pueblos poseen sus propios rebaños: las manadas que, como instituciones, poseen

${ }^{3}$ Sobre esta forma de enfrentar a los espíritus que moran en los cerros por medio de una atadura mediadora cf. Rivera (2000: 274-275, 278). 
las comunidades del valle del Chancay están adscritas a los santos epónimos de los pueblos. Sus imágenes son engalanadas y sacadas de la iglesia en el momento en que el ganado ingresa en el pueblo para ser identificado. Pero si el ganado está directamente adscrito a los santos católicos, también lo está, indirectamente, a los espíritus tutelares de los cerros donde mora. Las canciones entonadas frente a las hornacinas de los santos, construidas sobre los manantiales de las alturas, aluden a estos espíritus llamados auquillos. Estos espíritus son considerados los dueños del territorio donde habita el ganado (y de los manantiales donde abrevan), por lo que los ganaderos dejan frecuentes ofrendas a estos espíritus en discretos parajes de sus majadas. Tal es el testimonio de Juvenal Casaverde, quien permaneció en Vichaycocha a fines de la década de 1970:

Por otro lado, se admite que esta primera generación de habitantes si bien ha "muerto"... no ha desaparecido totalmente, ya que ellos actualmente "viven" dentro del mismo territorio vichaycochano, pero en una "dimensión diferente" manifestándose a los pobladores a través de sueños, manantes, sitios arqueológicos y otros medios. Dentro de la ideología local se considera que los abuelos tienen "vida activa", son "dueños" de la fauna silvestre, tierras y ganado de los pobladores, bienes que otorgan a sus descendientes. Además, velan por el bienestar de los hijos del pueblo, los cultivos y el ganado. Por su parte, los vichaycochanos... en reconocimiento a los bienes y protección que reciben, deben retribuirles con rituales, ofrendas y oraciones apropiadas en situaciones prescritas (Casaverde 1979b: 25).

La concepción del auquillo o espíritu tutelar de los cerros como "dueño del ganado" explicaría, además, las elaboradas ceremonias ayacuchanas realizadas con ocasión de una simple transacción comercial de ganado:

Cuando el campesino deba entregar ganado mayor (vacuno o equino) al comerciante, se realiza previamente la ceremonia del Velakuy a San Marcos (retablo que representa al panteón de santos cristianos) y al Illa... que representa al wamani en un mismo "altar" rústicamente preparado. Esta ceremonia... [es] previa a la captura de los animales en sus querencias. En el desarrollo del velakuy hay intercambio de regalos entre el wamanguino [el comerciante] y los campesinos y ofrendas conjuntas a los dioses tutelares (Wamani o Apus) (García 1989: 62).

También nos acercan al sentido de las palabras que un criador dirigiera a Ulpiano Quispe mientras ascendían a las alturas para enterrar los saldos de su rodeo:

Sólo tengo miedo porque es el último día de agosto... las puertas del cerro están todavía abiertas; este mes y el "loco" febrero son los más peligrosos [...] Un huarcaíno [hombre de la comarca] se había quedado dormido en Pishqa Pukyo [Cinco Manantiales, paraje donde los criadores entierran las señales]. Tenía coca en la boca, un cigarrillo encendido y una porción de tuqra en la mano. Al des- 
pertarse y aún dormitando, escuchó que los "cerros wamanis" se estaban llamando; uno decía: "le hubieras aprovechado el corazón, habrías podido castrarle...". Y el otro respondía: "no se puede, apesta su boca, tiene fuego en la misma y está mascando piedra". Al escuchar todo esto, el hombre se agarró los testes pensando que los había perdido, pero no le había sucedido nada. (Quispe 1969: 39)

Parece tratarse, además, de un hambre avasallador, absoluto. Quien entra en su poder, en su boca o sus puertas, en adelante no pertenece más que a él:

Cuando el cerro "come" [a las personas] dice que lleva alma y cuerpo, entonces ya no podemos presentarnos ni a Dios. (Ibid.)

El auquillo es, además, enamoradizo. En Huancavelica aseguran que el cerro abre sus puertas a ciertas mujeres que, en adelante, sólo serán para él (Fuenzalida 1980: 160). El espíritu de los cerros se delinea como una entidad masculina, agresiva con los varones, seductora con las mujeres:

Estas potencias [las que animan la naturaleza] son sexuadas, a veces en grado sumo. A menudo codician al humano de su sexo opuesto o envidian y rivalizan con los del suyo propio (Ortiz Rescaniere 2001 [1993]: 86).

El término quechua usado para designar los cerros parece refrendar nuestra intuición: orqo es, además de montaña, macho (ulqu, Cerrón-Palomino 1976; y orqu, Parker y Chávez 1976). El código sexual que adoptan las relaciones entre los espíritus de los cerros y los hombres se manifiesta a modo de infecundidad. Los hombres corren el riesgo de ser castrados. Las muchachas que entran en su poder son negadas al contacto con un varón: éste moriría del kantcha o señal. Pero, además de infecundos o esterilizantes, los espíritus de los cerros parecen estar asociados a lo salvaje. Dentro de Cinco Manantiales mora una enorme serpiente $-\mathrm{y}$, sólo por verla, un hombre ha perdido un brazo por el resto de su vida(Quispe 1969: 38). Serpientes suelen ser los primeros amantes de las doncellas retenidas por sus padres (Arguedas 1949). O pueden ser la prueba del adulterio de una mujer y causa de la enfermedad de su marido (Ávila 1975 [¿1598?]: 38). Se reitera, pues —en el mito del siglo XVI y en el contemporáneo-, la negación de la unión humana: la serpiente amante no puede engendrar sino culebrillas (que la moza aborta y los hombres destruyen), y el adulterio de la esposa no es sino la negación de la pareja, es decir, del vínculo por medio del cual la sociedad regula la reproducción humana. La asociación con los amores salvajes o ilícitos parece abarcar pues aquella otra que creímos encontrar relacionada con los espíritus tutelares de los cerros: la infecundidad.

El auquillo mora, pues, fuera del pueblo, es decir, fuera del centro 
de actualización de las normas sociales ${ }^{4}$. En Viscas (otra comunidad de la sierra de Lima), las autoridades del rodeo pasean una cruz por las casas de los ganaderos, quienes la atavían de collares (llamados wallchapas) y proveen de hojas de coca. Esta cruz es entregada a los vasallos para que la lleven hasta los hitos más altos del territorio de la comunidad. Este rito de reafirmación del territorio es común a muchas comarcas andinas. Y delimita, no sólo el territorio de los habitantes del pueblo, sino también el hábitat del ganado (del que no puede salir sin perjuicio de sus dueños). Enfatiza los parajes altos donde vive el ganado: los pastizales de propiedad comunal donde cada criador conserva el ganado de su familia. El traslado de la cruz obedece, pues, al mismo propósito que el rodeo: la buena administración del ganado.

Las cruces marcan una característica propia y exclusiva de los hombres. Los habitantes de los Andes emplazan cruces y capillas en los caminos que salen de sus pueblos: señalan así los límites entre su villa y las afueras. Pero, la cruz enviada a los hitos está, además, cargada de productos cuidadosamente reunidos por todos los ganaderos $-\mathrm{o}$ sea, los miembros adultos y casados de la comunidad-. Las guirnaldas ${ }^{5}$ son ela-

‘ Tristan Platt anota en uno de sus artículos un término, jurq'u, que "significa 'lugar salvaje' a la vez que 'espíritu de la montaña" (1980:161).

5 En la herranza de la sierra de Lima se llama "flores" a la huamanripa y la viraviray (que, sospechamos, es una variante de la huila-huila del valle del Mantaro), especímenes que suelen crecer sólo arriba de los $3500 \mathrm{~m}$. La flor usada en las guirnaldas, y en las ofrendas dejadas en los manantiales, no es de altura, sino de las regiones cálidas: el clavel. Creemos que las flores usadas en los Andes para realizar abluciones contra el "susto" (enfermedad muchas veces ocasionada por la agresión de los espíritus de los cerros) son también de este tipo. Las flores de altura, por su parten, son también muy usadas en los ritos andinos de identificación del ganado. Su número y variedad parecen ser tan grandes como poco estudiadas. En el departamento de Junín (provincia de Jauja) fueron anotados por Arguedas (1953: 267) los siguientes especímenes: Lima-lima (Ranunculaceae.Renúnculus), Sumaj-sunchu (Gentianaceae. Gentina), Uwishuwish (Compositae. Senecio tridentatus DC), Sura-Sura (Gramineae. Calamagrostis ovata (Presl) Steud), Cuchi-chrupa -traducible literalmente como "rabo de chancho"- (Polipodiaceae. Polypodium), Mishi-chrupa -traducible por "rabo de gato" (Lycopodiaceae. Lycopodium), Cala hualash - ajoven desnudon- (Polipodiaceae. Polypodium crassifolium), Oqcha (Compositae. Achirocline), Mata-mata (Compositae. Tafalla sp.), Huila-huila macho (Compositae. Culcitium canescens H. ct. B), Huila-huila hembra (Compositae. Culcitium nivale H.B.K.), Raki-raki (Polypodiaceae. Asplenium), Waqchur o Huamanripa hembra (Compositae. Senecio culcitiodes Wedd). Cerrón-Palomino (1976a) agrega una flor más para esta región: Chinchimali. En el departamento de Huancavelica, Fuenzalida (1980:165-166) anotó las siguientes: Utkunlipa, Maseta, Urqunwayta (clavel rojo), Kuyakuya. Y Quijada Jara (1957: 20) estas otras: Qantu, Inkil morada, Waman-sara, Sallquntuy, Qori-waylla, Escorsonera, Sumay-chunchu (No sabemos si se trata de una flor distinta de la citada por Arguedas y Cerrón-Palomino como sumaq-sunchu). 
boradas por las mujeres casadas del pueblo y las hojas de coca son donadas por los hombres maduros y cabales, cada uno debe agregar un puñado de coca al bulto que lleva la cruz. Símbolo de la vida religiosa, la cruz es además sometida a la impronta de los hombres y su mundo de parejas cabales y contribuyentes al bien común. La confirmación de la propiedad de los territorios de puna $-\mathrm{y}$ del ganado que incluye- es, pues, refrendada con las dos características que representa el emplazamiento de la cruz ataviada: la fe y la formalidad de los hombres ${ }^{6}$.

A esta oposición espacial parecen agregarse otras dos: contrario a la reproducción normal de los hombres y de su sociedad, el ámbito de las alturas se adscribe a los amores iniciales que los jóvenes sostienen allí con seres salvajes como serpientes o buitres. En 1962, Emilio Mendizábal Losack recopiló este testimonio de un criador de Pacaraos (valle de Chancay):

Los auquillos son personas que viven dentro de la tierra, salen por donde sale el agua del manantial. Los auquillos cuidan los animales... En época de rodaje sale con su tinya. // cuando la luna está llena... sale tocando tinya, sale a ver sus animales. Cuando vamos a la altura, tienen... que invitar con coca, cigarrillo, ron, diciendo: Awkillo, aweoloy, chaqchapakuri, hirka, yaya ${ }^{7}$. Las hojas de la coca de la mesa (mantel ceremonial extendido en el suelo) escogen, lo hacen polvo y le soplan. Le invita con ron, lo echan un poco, y le dicen: "ayúdame, acompáñame". // El Awkillo ayuda cuando en las casas lo ofrecen con coca y cigarro... En la altura cuida el ganado (Mendizábal 1964: 95-96).

El espíritu de los cerros - habitante del mundo subterráneo- es, pues, el dueño del ganado. Dado que éste mora en su territorio, los hombres deben reverenciar periódicamente al auquillo. El ganadero de Pacaraos prosigue:

Cuando en la chacra se tira una piedra al manantial, lo fastidia [al auquillo], entonces hace daño. Cuando lo conoce al dueño (de la chacra) no le hace daño.

\footnotetext{
${ }^{6}$ Las hojas de coca y las flores de los bajíos participan también de las ofrendas dejadas en las hornacinas y manantiales donde se invoca a los espíritus tutelares de los cerros (llamados "auquillos"). Pero si los elementos son los mismos, sus usos parecen oponerse simétricamente. Si los encargados de llevar la cruz eran jóvenes y solteros ("vasallos"); quienes ofrendan a los auquillos son adultos y casados ("mayordomos del ganado"). Mientras los vasallos atraviesan los campos para reafirmar las propiedades del pueblo, los mayordomos van en romería venerando las hornacinas de los auquillos y los santos católicos. Aquellos dan inicio al rodeo en un ambiente de beligerancia y entusiasmo, estos cierran las celebraciones en un clima de solemnidad.

7 Mendizábal traduce estas líneas del siguiente modo: "Señor, abuelo mío, mastica las hojas de coca, montaña, padre, ayúdame, acompáñame" (1964: 95), y consigna que esta invocación era repetida por los ganaderos también antes de proceder a identificar su ganado (1964: 114).
} 
Por la situación es diferente el de la chacra con el de la altura, pero es el mismo... El Awkillo es dueño de todo (Mendizábal 1964: 118).

Este testimonio coincide con nuestra observación del peregrinaje a los manantiales en Vichaycocha. Considerar al auquillo como el amo del agua, nos aproxima a otro ciclo ritual de singular importancia en los Andes: la limpieza anual del cauce que trae las aguas de las manantiales a las chacras del pueblo.

Algunos rituales, como la herranza, funcionan como un punto crítico: la envidia, la cólera del cerro es aun más temible ahora que el ganado será recobrado por los hombres. Un diálogo entre dos jóvenes comuneros (que ocupaban el cargo de alguaciles y que, por lo tanto, debían elaborar los arcos construidos sobre la puerta del redil) parece aludir a esta tensión. Dos jóvenes —escuchados en 1962 por Mendizábal Losack (1964: 118) durante el rodeo de Pacaraos- explicaban la ornamentación del arco con fuentes, cubiertos, copas de plata, billetes, monedas, una media luna de plata y una corneta de cuerno, aludiendo "a alguien que vendría a comer de esa mesan.

Las valoraciones en torno al espíritu que domina las alturas parecen influir hasta en las concepciones respecto a los hombres que moran allí de modo más o menos permanente: los pastores. En el valle del Chancay se les da el nombre de llacuaces a quienes cuidan el ganado menor en las estancias:

Tanto en el pasado como en la actualidad los habitantes de esta zona [las áreas de pastoreo situadas a más de $4,000 \mathrm{~m}$. sobre el nivel del mar] han debido desempeñar un papel importante en las relaciones sociales de los pacareños, quienes se refieren a ellos denominándolos "caseros", "taytalas" o "llacuaces" (Adelaar 1986: 3).

Se llama "llakuas", además, a la gente arisca y poco refinada. En setiembre de 1975, Amadeo Alejo Núñez, habitante de la provincia de Cajatambo (departamento de Lima) comenzó su relato explicando: "Una pobre mujer de las alturas, una llakuas..." (Ortiz Rescaniere 1980: 57) ${ }^{8}$.

\footnotetext{
${ }^{8}$ Estos juicios son tan arraigados en la mentalidad de los habitantes de los Andes, que parecen haber influido aun en las descripciones de corte económico poco atentas a la distinción entre prejuicios y prácticas. Encontramos un ejemplo de ello en una de las etnografías realizadas en el valle del Chancay:

"Los pastores constituyen un grupo de status especial; a pesar de haber llegado hace tres generaciones a la comunidad se les sigue considerando como forasteros; son hostilizados y despreciados pero se les tolera por cuanto se considera que constituyen un mal necesario, tanto que formalmente se ha adjudicado
} 
Los comuneros del valle de Chancay solían embromar a los hombres que habitaban en los cerros de modo permanente. Decían que ellos eran como el ganado y que había que marcarlos. Estos habitantes de las alturas parecen asociados aun con las tímidas vicuñas silvestres que habitan esos parajes. El nombre quechua dado al pastor, laqwash (Adelaar 1982: 46) - Siendo llakwas y "llacuaz" las formas castellanizadas-, coincide con el término usado, en la variante huanca, para designar aquellas hermosas criaturas: llaqwa (Cerrón-Palomino 1976: 82). Los pastores, en las regiones donde tienen las reses a su cuidado, son una suerte de propietarios de hecho. Conviven con el ganado en las alturas, cuidan de su alimentación y traslado diario a los rediles de las estancias. Sólo una vez al año conducen las manadas al pueblo de sus verdaderos dueños. Las canciones que entonces entonan los pastores nos muestran un poco las ideas que predominan en torno a su vida: sus sufrimientos por la mezquindad de los ganaderos y por la estrechez que pasan en los alejados parajes donde deben permanecer. José María Arguedas (1953b: 270-293) recopiló varias composiciones de este talante en el valle del Mantaro:

Miserable mayordomo

miserable patrona,

pagallaita mañapti

calzadoquita lanti nimanqui

¡manam calzadoypis cancho!..

huagujo jina almursunhuan,

¿chaillatachon yachanqui

miserable patrón?

\author{
Miserable mayordomo \\ Miserable patrona \\ Cuando te pedí mi paga, \\ "te he comprado calzado" - me dijiste \\ ¡Yo no tengo zapatos! \\ Almuerzo jugo de espinos \\ ¿Sólo eso sabes darme \\ miserable patrón? \\ Canción de herranza de carneros recogida \\ en Quicha, distrito de Concepción, depar- \\ tamento de Junín.
}

Miserable patroncitoy, Cocallaiquipis fardonpami

Miserable patroncito.

Tu coca por fardos,

me ofreciste patroncito.

Tu aguardiente también,

por toneles me ofreciste.

Aguardientellaiquipis, tunilnimpan nimalaiqui,

a alguno de ellos calidad de comunero aunque en la práctica se vea imposibilitado de ejercer plenos derechos puesto que, por la naturaleza de su trabajo, todos ellos residen fuera de los núcleos urbanos de la comunidad —en las estancias diseminadas en los terrenos de la zona alta-, lo que a su vez implica que el contacto y la comunicación con el común huayopampino sea sumamente reducido. (Casaverde; Degregori; Fuenzalida; Golte; Valiente; y Villarán 1982 [1968]: 260). 
cigarrollaiquitapis,

rollollampa nimalaiquim.

Maitan, maitan patroncitoy, quipe bolsa patroncito, miserable patroncitoy miserable patroncita.

Animalquihuan, caicho sufrí Ujsha pajuininta, chicarhuaita ${ }^{9}$ Hualajullata miculcul

Cuidallá uwishllaiquita.

Manalla chamunquicho, ni yalpamanquicho Halalcul, hualalcul, liljalamú caminocajllata Esto será o aquel será niptipis manam caycho

Sino huarahuay shipillam analcamun, Aquél será niptipis shuito lumillam licalimun

Yantuillam quimlamun...

Uwishllaiquita, quitaman compadrillaiqui Ñujallá larstachalai chucullaiquihuan Puntai punchallaiquihuan

Cuidallá animalquita ¡miserable patrón!

Olon, olon, polí

Aan, aan, polí

Tamyachupis polí

Usiachupis polí

Patroncitochallay...

Tu cigarro también

por rollos me ofreciste.

¿Dónde están? ¿Dónde están, patroncito de apretada bolsa?

Miserable patroncito, miserable patroncita.

Canción de herranza de vacas recogida en Yauli, provincia de Jauja.

Con tus animales sufro aquí; de las espinas, de la paja y del chicarhuay el fruto comiendo,

¡Cuido tus ovejas!

Tú no vienes ni te acuerdas de mi.

Este día al otro miro el camino, "éste será aquél será", digo iy no eres tú! Sólo el huarahuay [ave de la puna] se acerca.

"Este será aquél será", digo: y no veo sino piedras alargadas

sólo mi sombra tendida de costado...

$\mathrm{Y}$ tu compadre el zorro me roba tus ovejas Mientras yo, encasquetado de nieve,

Con la neblina emponchado

Cuido tus animales imiserable patrón!

Canción de herranza de ovejas recogida en Yauli, provincia de Jauja.

Cerro y cerro anduve

barranco y barranco anduve

en la lluvia anduve

en el tiempo de la sequía también anduve patroncito...

Canción de herranza recogida en Punco, Andamarca, Concepción. Informante: Sara Alcántara.

\footnotetext{
${ }^{9}$ Por experiencia personal conocemos la chicarhua y la hualaja. Pero no hemos podido hallar el nombre científico de estas dos plantas silvestres y comestibles de la puna; un tubérculo, la primera; y una especie de nopal, la segunda.
} 
Es de notar que el espíritu de los cerros no es siempre una entidad agresora (aunque siempre significa alteridad). Es sólo en ciertos contextos - uno de los cuales es la herranza- cuando adquiere los valores que hemos señalado hasta aquí. Y tal característica parece común en la religiosidad andina:

La ambivalencia es remarcable en el caso de los wamani, apus, o dioses de la montaña. Los wamani son los espíritus de ciertas montañas que protegen, siguiendo su importancia, a una parcialidad, a un pueblo o a una etnia entera. Se les rinde culto por su protección, porque velan por el orden de la sociedad presente. Son personificados en las figuras de un cóndor, de un mestizo. Se les asimila también a Santiago Apóstol. Pero, al mismo tiempo, por ser dioses vencidos frente al catolicismo, poseen carácter demoníaco; en determinados casos se tragan a los hombres y a sus ganados. Son aéreos o telúricos, dioses o diablos, según el contexto.// A diferencia de la tradición cristiana, donde el bien y el mal son dos fuerzas irreconciliables y antagónicas, en la religiosidad andina lo divino y lo demoníaco son caracteres que revisten un mismo personajes según el momento, el contexto o el ángulo de donde se le mire (Ortiz Rescaniere 1986: 212-213).

El espíritu de los cerros tampoco es el único personaje que puebla las alturas. Allí construyeron sus casas los gentiles, miembros de una humanidad anterior. Los gentiles adquieren distintos nombres según la región: ch'ullpas, achachilas, ñaupa machus, abuelos y viejos. Su renuencia al intercambio de bienes (Ansión 1987: 83-115) es ilustrada mediante los condimentos básicos de la cocina: ají, sal, cebolla, y que es análoga a la aversión que encontramos en los espíritus de los cerros hacia la pareja humana estable. La comensalidad y el intercambio de bienes y mujeres no parecen pues sino transformaciones de un mismo tema: la negación de la cultura (cf. Rivera Andía 2000b). Negación que, por lo demás, parece asociada a la noche, como lo muestran las palabras con que Lorena Córdova contó el fin de los gentiles a Willem F. Adelaar ${ }^{10}$ en Pacaraos:

Las casas de los gentiles estaban muy bien construidas en las alturas, en los cerros. Se habrían escondido allí para no morir. Pero, allí dentro, se secaron: el día que ascendieron los dos soles en el firmamento, ese día murieron (1986: 86-87).

${ }^{10}$ El fragmento original de este relato es el siguiente (la transcripción y traducción pertenecen a Adelaar):

... wayin pirqashaqa chumaq. 5. altutraw seerrutraw chumaq waynkuna pirqashqa. 6. say ruritraw sakishqa bentilkuna. 7. saa ishkay wilkayarqarqamuptintraa pakakarirqa mana wañunampaqtri. 8. wañurqa...

...Sus casas [de los gentiles] estaban muy bien construidas. 5. En las alturas, en los cerros, sus casas estaban muy bien construidas. 6. Y ahí adentro (se) secaron los gentiles. 7. Ellos se habrían escondido para no morir, cuando subieron los dos soles. 8. (Sin embargo) murieron... 
Ahora sólo resaltemos que esta humanidad vieja permanece aun después de su aniquilación: representan un saldo del pasado en el mundo actual, un vestigio presocial (Cereceda 1990: 72-80) que se manifiesta a los hombres a través de sueños, enfermedades y represalias (Arguedas e Izquierdo 1987: 365; 1989:13, 37). También pueblan los solitarios pastizales de la puna, implacables degolladores que seccionan sus cadáveres para extraer su grasa en las profundidades de las cuevas (Arguedas 1953: 218-228).

Aún más asombrosos que los degolladores, son los toros de fiereza excesiva que arremeten y despedazan, no sólo a los hombres que encuentran en su camino, sino incluso a los mismos degolladores (Arguedas 1953: 220-221). El peligro, la ausencia de reciprocidad, parecen ser la impronta de estos personajes (Wachtel 1997 [1992]: 68). Sin embargo, el ganado, a veces sobrenatural y salvaje, es doméstico al mismo tiempo. Las reses tienen una fuerte preferencia por la sal que sus dueños satisfacen gustosos: en todos los Andes se regala a las reses, sobre todo si están preñadas, con una buena porción de sal por lo menos una vez al mes (Degregori et. al. 1973: 53). Siendo, pues, bestia, el ganado gusta de un elemento asociado con la cultura. En el valle del Mantaro (provincia de Jauja), hemos observado que los niños recién nacidos son "bautizados" en una ceremonia hogareña en la que se reza un padre nuestro, se les llama por su nombre y se les pone un poco de sal en la lengua. Un pastorcillo encuentra en su choza a una hermosa muchacha que cocinaba para él en secreto. Este "encanto", sin embargo -que pide al joven mantener en secreto su convivencia-, carece de un elemento esencial en su cocina: no usa la sal. Nosotros recopilamos este relato en el valle de Chancay (Rivera Andía 2003):

\footnotetext{
Allí, en la puna, había una mujer que era un encanto. Se vestía con prendedores grandes de plata, con manta y pañolón. Seguramente se lavaría el pelo con la cola de caballo [una hierba silvestre utilizada con tal fin], porque dicen que sus cabellos brillaban. Esta hermosa mujer se enamoró de un joven que pastaba su ganado y vivía solo en las alturas. Entonces, el joven comenzó a encontrar comida y cosas ricas en su casa. Era misterioso. Pensaba que se trataba de su mamá. Pero se preguntaba: “¿Por qué no me esperarán a comer?”. Así, regresaba cada día a su choza y encontraba siempre la comida lista. Pero a nadie más. Hasta que un día se queda a vigilar y entonces descubre a la hermosa muchacha. "Tinku" le dicen en quechua a eso.

Bueno, el pastor y la mujer se juntaron y convivieron. La muchacha le cocinaba, pero no sabía comer sal. ¡Ojo, no comía sal! Ella le hacía todas las cosas, pero le puso la condición de que él no debía avisar a nadie que tenía una enamorada. Desde que se juntaron, el joven se había convertido en el rey del ganado ovino. Ella le dijo que si él le avisaba a alguien, todo su ganado se iría a la ruma [se perdería]. Pero un día, cuando bajaba al pueblo, le preguntaron:

- ¿Cómo usted puede vivir sin mujer, sin nada?
} 
- iSí tengo, si quieres anda a ver! - responde el cojudo [estúpido].

Entonces han ido a visitarla. Y dicen que, como ella tenía la capacidad de saberlo todo, corrió. Y entonces se abrió la tierra, se abrió un hueco y entró ella junto con el ganado. Después se cerró la tierra y todo quedó igual. El pastor se quedó solo y con sus pocas ovejas. Y todo porque le avisó a su familia.

Esta misma carencia ha sido señalada entre los ogros que habitan los parajes solitarios. Estos personajes antropófagos tienen tantas similitudes como nombres a lo largo de los Andes. Algunas de los nombres que adoptan son: mama buaca, mama guardona y urcu tayta en la sierra sur ecuatoriana; chificha en la sierra norte (Gutiérrez 1988: 286); achikee, achkay y wa-kón (Ortiz Rescaniere 1973: 39-58) en la sierra central peruana; y aracrayca o racrayca (Souffez 1992: 249-274, y Benavides s/f) en la misma cuenca de Huaral.

La mama-huaca... se alimenta de una manera peculiar, diferente a la que es habitual en los hombres... no conoce la sal y come sin sal todos los alimentos... Ya sea por la clase de los productos alimenticios que emplea, ya sea, en otros casos, por la falta de condimento, su comida es una comida no adecuada. La inadecuación de la comida de la mama-huaca es la que corresponde a la propia de alguien "salvaje", "gentil", no cristiano, no humano, "natural" (Gutiérrez Estévez 1988:287).

El ganado vacuno y los manantiales, focos de la atención de los rituales de ciclo económico, oscilan entre dos mundos. Son indispensables para los hombres y son utilizados continuamente en las actividades humanas. Pero al mismo tiempo, el espacio al cual se encuentran adscritos es el espacio ajeno a la villa donde los hombres habitan. Este espacio es el mismo en el que encontramos al espíritu de las montañas. Los extensos pastizales de las alturas son el hábitat del ganado y el lugar común de los manantiales de agua. Las entidades que moran este espacio parecen configurar un alter, al cual los hombres deben arrebatar, usurpar el agua y el ganado. Los ritos de ciclo económico buscarían una solución a este conflicto entre estos dos ámbitos contrastados. La hipótesis en torno a los valores asociados a cada uno de los ámbitos en cuestión ya ha sido elaborada por Manuel Gutiérrez Estévez a partir de su estudio de los personajes asociados a la noche y los cerros:

... los [relatos] que tienen por figura central a los dueños del cerro... parecen referirse... a la oposición entre naturaleza y cultura. Correlativa a esa oposición es la de tiempo pasado vs. tiempo presente, y de ésta se derivan las funciones etiológicas que parecen corresponder a los protagonistas míticos de estos relatos... [que] simbolizan a la naturaleza frente a la vida social ordinaria representada por el pueblo y las tierras cultivadas colindantes. Conforme a un esquema no específicamente andino, sino común a muchas otras culturas, la representación 
de la cultura lleva consigo, también, la de un tiempo pasado (de "gentiles" o ñaupas, en este caso), frente al tiempo actual habitado por los "renacientes"... // El espacio (el cerro frente al valle, o lo alto frente a lo bajo) se vincula al tiempo (el pasado frente al presente), y ambas categorías, entrelazadas, son susceptibles de ser expresadas, de un modo más abstracto y por la cualidad que las subtiende, como si fueran manifestaciones particulares de la conceptualización de la identidad más genérica (la naturaleza frente a la cultura) (Gutiérrez Estévez 1988: 286).

Esta asociación de la naturaleza con lo ajeno y lo pretérito, en oposición a una cultura ligada a lo propio y el presente, también ha sido señalada por Verónica Cereceda a propósito de su estudio de los códigos ópticos presentes en los tejidos andinos:

... este lenguaje, con su plano de la expresión y su plano del contenido, está siendo utilizado por el pensamiento para articular, a su vez, contenidos como Ego, Alter, cultura, precultura, etc. Es lo que sucede en las semióticas llamadas "Connotativas" donde un texto determinado se comporta —en su totalidad de significante y significado- como si fuese solamente el significante de un nuevo sentido, que podríamos definir aquí como un sistema de valores: una organización de ciertos principios fundamentales (Cereceda 1990: 97).

Las características de los personajes asociados a la morada habitual del ganado, la pampa, nos hacen comprensibles la preocupación y cuidados impuestos por algunos ritos del rodeo. Los ritos de identificación del ganado representan, pues, una suerte de desafío a estas entidades. Y este desafío a las alturas es, entre los habitantes de las villas campesinas de los Andes (en contextos como el ritual señalado), una forma de enfrentar la alteridad, una forma de afirmar en qué consiste ser un hombre cabal. Intentemos resumir las consideraciones esbozadas hasta ahora:

1. Los espíritus tutelares de los cerros y los personajes que habitan en sus dominios poseen características que los torna peligrosos (sobre todo en ciertas épocas del año marcadas por los rituales de ciclo económico): silvestres, ajenos, nocturnos y ligados a los tiempos pretéritos, aunque presentes en el mundo actual.

2. Las entidades que pueblan los extramuros de las villas andinas rompen una de las reglas fundamentales de la vida en sociedad: el intercambio entre familias, sea éste de bienes o de parejas.

Ahora intentaremos corroborar estas consideraciones a través de un examen breve de las connotaciones asociadas al término que designa este territorio: pampa. Se trata, por ahora, del esbozo de una intuición basada en algunos estudios previos (Cereceda 1990). 
LA ONDISTINCIÓN PROPAGADA: APROXIMACIÓN A LAS CONNOTACIONES Y METÁFORAS EN TORNO A LA NOCIÓN DE PAMPA

Un cuento que oímos en el valle de Chancay (Rivera Andía 2003) cuenta la lucha de los primeros tiempos entre dos "cerros": Kilupallqa y Umanwillca. El objeto final de la lucha es el logro de una distinción fundamental inexistente en los "tiempos antiguos": la sexual. Se trata de un tiempo lleno de penumbra y carente de contrastes. Cuando Kilupallqa atraviesa con su honda a Umanwillca, ésta queda convertida en hembra. Y Kilupallqa logra ser el macho. La carencia de distinciones asociada a las alturas es un saldo de ese pasado.

El espacio que circunda a una villa andina es designado con un vocablo nativo, adoptado por el castellano y compartido por el quechua y el aymará: pampa. Las connotaciones más comunes que este término presenta en los primeros léxicos coloniales del siglo XVI parecen aludir también a lo ajeno y a lo silvestre. Los dos léxicos coloniales más importantes, González Holguín (1989 [1608]: 275) y Bertonio (1984 [1612]: 85, 246), parecen confirmarlo. Bertonio consigna pampa, no sólo como eel campo, o todo lo que está fuera del pueblo, ahora sea cuesta, ahora llano", sino que agrega: «baldía cosa sin dueño». González Holguín declara con llaneza que pampa es "pasto, çauana, o campo", pero asocia pampa a otro término: purum (1989: 275), que traduce (1989: 297-298) como:

Purum runa poques

Purum soncco

Purum aucca

Purum allpa o chacra

Purumyachini allpacta

Purum sonccoyoc purum yuyayniyoc

\author{
Barbaro saluaje sin ley ni Rey. \\ Indomito no sujeto ni enseñado ni doctrinado. \\ Los no conquistados enemigos \\ Tierras yermas o dexadas de cultiuar. \\ No cultiuar, desamparar tierras \\ El que no trata ni dessea saber cosa buena de \\ su saluacion ni hazer nada por ella ni se dexa \\ cultiuar ni ayudar a dar fructo
}

Bertonio también establece la misma asociación: "pampa hauqe; vel puruma haque", y traduce del siguiente modo:

Puruma caura Carnero que aun no ha sido cargado

Puruma uraq

Tierra por labrar. O la que ha mucho que no se labra.

Comi puruma uraq

Tierra nunca labrada (1984: 278)

El término purum se relaciona además con una humanidad anterior, como los gentiles y los tiempos antiguos: "Puruma... Tiempo antiquísimo, cuando no havia sol, según imaginaban los indios, ni muchas cosas de 
las que hay agora" (Bertonio 1984: 178). En la misma comunidad de Vichaycocha existen unas ruinas prehispánicas que los lugareños denominan "Purunmarca" y conocen como morada de los "abuelos".

Y agregan, además, otro significado: lo indistinto (este esfuerzo tiene, por lo menos, dos importantes precedentes: Tristan Platt 1980 y Verónica Cereceda 1990). Esta categoría parece expresarse simultáneamente a través de varias metáforas (táctil, óptica y sociológica) que ahora trataremos de mostrar.

La primera connotación de pampa es la de lo llano (o indistinto en cuanto a superficies). Bertonio traduce pampa como: "Todo lo bajo respecto de la mesa, o poyo, la tierra llana" (Bertonio 1984: 246). Domingo de Santo Tomás lo corrobora: "campo raso como vega" (1951 [1560]: 335), "cosa llana generalmente". Y también el léxico anónimo editado por Antonio Ricardo: "allanar el suelo", "campo, plaza, suelo, llano". El vocabulario de González Holguín (1989: 275-276) da varios ejemplos:

$\begin{array}{ll}\text { Pampa... } & \text { Suelo llano o llanada } \\ \text { Pampapanpa } & \text { Llanuras } \\ \text { Pampañan } & \text { Camino llano y camino real común } \\ \text { Pampachani } & \text { Allanar el suelo }\end{array}$

Es este el significado que más señalan los diccionarios contemporáneos dedicados a los distintos dialectos quechuas: la llanura: pampa; y la nivelación de superficies: pampay, pampachiy, pampachay, pampatsaay (Cenepo et. al. 1976; Quesada 1976; Cerrón-Palomino 1976a; y Parker et. al. 1976). Las superficies lisas, sea la de una mesa o la de una extenso campo raso, se definen por su carencia de protuberancias o de simas. Careciendo de los accidentes que, las más de las veces, nos ayudan a delimitar las secciones o partes de los espacios que nos circundan, dificulta, pues, nuestra percepción.

La segunda connotación que encontramos en el término que designa las alturas es lo monocromo (o indistinto en cuanto a tonalidades). Pam$p a$ indica, para las tejedoras entre las cuales Verónica Cereceda realizó su trabajo de campo, un espacio dejado a merced de un solo tono, que, continuo y uniforme, no es sometido a ningún contraste ni interrumpido por ningún diseño (Cereceda 1990: 93) (ver esquema N.. 1). El efecto es similar al de las llanuras: una tela inundada por un sólo color, en la que no se han establecido contrastes, nos impide captar diferencias o imágenes dentro de ese fondo en el cual la mirada parece extraviarse.

Una tercera connotación es la de lo común (o indistinto en cuanto a características). El diccionario anónimo del siglo XVI traduce pampa por "cosa común" (citado en Platt 1980). González Holguín es más abundante en ejemplos: 


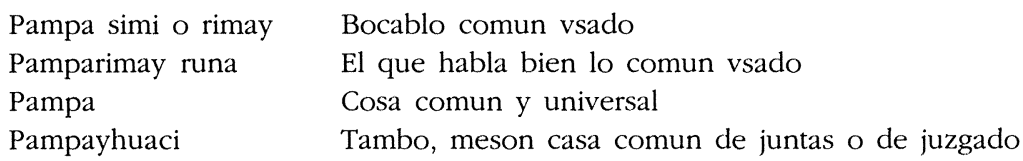

Como las superficies sin tolondrones o sin contrastes, el énfasis en las características comunes entre los hombres pasa por alto las particularidades y distinciones que los hombres establecen entre sí. Pasamos aquí de un nivel sensible (el del tacto y la vista) a otro, relacionado con los hombres y su vida en sociedad.

La cuarta connotación que encontramos en el término pampa es la de lo concordante (o indistinto en cuanto a oposiciones). Así, en González Holguín hallamos anotado (1989: 276):

Panpachani huchacta

Checninacuscanta pampachani

Aucca tucuctam pampachani Aucactam pampacharcuni Aucactam cunacta pampacharcuni Panpachacuni sonccoyta Diosman
Çaçacacta, o huchap çaçacay ninta. Allanar las dificultades del negocio.

Hazer amistades entre los enojados, o reñidos, o enemigos.

Allanar a los alçados, o reuelados.

Acabar la guerra.

Rendir los enemigos.

Rendirse a Dios.

Esta acepción es corroborada también en los vocabularios de las variantes regionales del quechua:

Pampachay

Perdonar, olvidar una ofensa (Cerrón-Palomino 1976)

Pampatsaay

Olvidarse (Parker et. al. 1976)

La concordancia entre términos beligerantes o contrarios aparece como una consecuencia lógica del énfasis anterior: en las características comunes que unen en vez de separar (más adelante veremos que esta acepción de pampa es la contrapartida "natural" de otro término homólogo pero "cultural": tinku).

Una quinta connotación se encuentra en los vocablos que usan el término pampa para referirse a lo equivalente (o indistinto en cuanto a jerarquías):

Pampalla

Pampa $\operatorname{simi}^{11}$ runa
Ygualmente a todos o distintamente, o no reparando con consideración

El hombre que tiene trato y comunicacion con todos, hombre de buen trato (González Ibid.)

11 Simi (shimi) puede traducirse como lengua, idioma o palabra. 
Pampa haque

Pampa soncco runa
Hacha Ampara, Ampara lokhtataraqui: Dadivoso, liberal, o pródigo que no repara en dar (Bertonio 1984: 246-247)

El amoroso, afable, que a todos trata y comunica y se da a todos, o llapamasoncco ${ }^{12}$

Ahora pasamos del punto de vista de lo colectivo (donde se resaltan los rasgos comunes de sus componentes y la concordancia entre sus partes) al del individuo. Según los términos que sumen a pampa, éste será excesivamente pródigo (en palabras, en afectos o en acciones), y no hará distingos entre los sujetos que trata.

En sexto lugar, descubrimos que pampa puede connotar también lo subversivo (o indistinto en cuanto a normas). Hay tres aspectos de la subversión contra las normas establecidas por la ley y el uso. La mujer que a todos se entrega:

Pampachusi

o pamparuna: Ramera, mala mujer (Bertonio 1984: 247).

Pampayruna

Muger pública, común a todos. // La mala mujer puta, ramera.

A la oposición que los amores primeros - "crudos", diríamos, usando la metáfora culinaria tan popular en diferentes culturas- sostenían con el hogar estable de las parejas cabales -O "cocidas" por la cultura-, ahora se agrega otra: a mujer que no se contenta con un hombre o que se entrega a todos sin distinción - que, en el otro plano equivaldría a lo "podrido"- Sea por carencia o por exceso, estamos, pues, en un campo semántico que parece empeñarse en negar los valores establecidos por la cultura de los hombres y su pueblo.

No nos hemos alejado mucho del concepto anterior: la mujer común a todos como los pastos que circundan al pueblo, parece aun uno de eso individuos pródigos en exceso. Hay, sin embargo - y esto aparentemente, pues los grandes estudiosos del quechua eran entonces miembros del clero-, un cambio de acepción: de la desproporción positiva o risueña estamos ahora frente a un exceso negativo. Esta connotación se refuerza con el siguiente ejemplo: la delincuencia del montaraz.

Sara pampachatha

Pampachani

Pampa haque
Quebrar la ley -literalmente: hablar o andar haciendo pampa- (1984:392).

Quebrantar la ley.

ver puruma haque, atimaa haque: Uno que no está sujeto a nadie, que vive a su albedrío (Ibid.)

${ }^{12}$ Soncco (shunqu o sonqo, según los dialectos) designa el corazón y, sobre todo antiguamente, todos los interiores. 
Puede irse contra el orden quebrando la ley, aplanando el terreno de acción como un llano en el cual no hay normas ni pautas que obstaculicen el paso; o viviendo alejado de las reglas sociales, como el rústico o el ácrata que "vive a su albedrío". Un último ejemplo de la subversión, lo proporciona la falacia, del cínico o del lenguaraz:

Pampalla juraycachac

El jurador a bulto sin consideracion de la verdad (González 1989: 275-276).

Pampalla simiyoc

Hablar sin distincion de todo i imprudentemente y sin recato.

Pampa llam rimani Hablar o biuir sin reparar o sin consideración, sin prudencia; hablar a bulto de todo.

La galería de personajes que atentan contra el orden parece elocuente por sí misma. El último ejemplo nos lleva a ahora a un séptimo punto: nos habla, además de sedición, de falta de tino.

Finalmente, podemos señalar una última connotación de pampa: lo confuso (o indistinto en cuanto a pensamiento). Al respecto hallamos:

Pampa haque

Uno que vive a poco más, o menos, sin consejo, ni prudencia (Bertonio 1984: 392).

Pampalla sonco pampalla yuyayniyoc

El distraydo en varias cosas y derramado en pensar (González 1989: 275).

Hemos intentado agrupar los distintos conceptos hallados en los vocabularios más importantes. No pretendemos haber sido exhaustivos, ni mucho menos definitivos. Se trata apenas de una fijación, de un esbozo de conceptos propios de lenguas tan ricas en dobleces y metáforas como el quechua y el aymará.

Este primer boceto, que esperamos sea útil para un análisis posterior, nos ha mostrado, pues, que los conceptos y valores asociados a un espacio que rodea a todas las villas andinas. Estas concepciones giran en torno a tres "ejes": lo ajeno, lo silvestre y lo indistinto. El peligro de las llanuras solitarias y de la ausencia de colores contrastados; la trascendencia de aquello que poseemos en común, nos equipara y nos hace concordar; la confusión y la subversión implícitas en la indistinción; la fascinación de lo ajeno; todo esto parece ser parte de las ideas recurrentes en la configuración de la alteridad entre las poblaciones campesinas de los Andes sudamericanos.

\section{BIBLIOGRAFÍA CITADA}

AdelaAr, Willem F. H. 1986. Morfología del quechua de Pacaraos. Lima: Centro de Investigación de Lingüística Aplicada. Universidad Nacional Mayor de San Marcos. Documento de trabajo n. 953 . 
Ansión, JuAn. 1987. Desde el rincón de los muertos. El pensamiento mítico de Ayacucho. Lima: Gredes.

ARGUEDAS, José MARÍA. 1949. Canciones y cuentos del pueblo quechua. Lima: Huascarán.

- 1953. Folklore del valle del Mantaro. Provincias de Jauja y Concepción. Folklore Americano 1: 101-293.

- y FRANCISCO IzQUIERDO Ríos (recops.). 1987. Folklore del pueblo de Araguay. Anthropologica 5: 5-39.

Ávila, FRANCISCO DE. 1975 [¿1598?]. Dioses y hombres de Huarochiri. Traducción de José María Arguedas). México: Siglo XXI, 2. ${ }^{a}$ ed.

BENAVIDES Estrada, JuAN Augusto. s/f [i1980?]. La comunidad campesina de Huascoy, estructura económico-social y realidad educativa. Lima: Editorial Universo.

BERTONIO, LUDOVICO P. 1984 [1612]. Vocabulario de la lengua aymara. Cochabamba: Ceres, Ifea, Musef.

BOREA, GIULIANA. 2001a. Ocupación y afirmación del territorio: estudio en cuatro comunidades del distrito de Santiago, Cusco. Tesis (Lic.). Pontificia Universidad Católica del Perú. Facultad de Ciencias Sociales. Lima.

- 2001b. Ritual de los linderos: limitando y recreando al grupo y su territorio. Anthropologica 19: 347-363.

CASAVERDE R., JUVENAL. 1979a. Individualismo y colectivismo: intereses divergentes en la economía de Vichaycocha (Huaral), en Campesinado y capitalismo: 9-19. Huancayo: Instituto de Estudios Andinos.

- 1979b. La descendencia omnilineal de los Andes, en Antropología Andina 3: 21-31. Qosqo: Centro de estudios andinos Cusco (CEAC).

CENEPO S., Víctor; MARINell PARK y NANCY WeBwer. 1976. Diccionario quechua San Martín. Lima: Instituto de Estudios Peruanos - Ministerio de Educación.

CERECEDA, VERÓNICA. 1990. "A partir de los colores de un pájaro...". Boletín del museo chileno de arte precolombino 4: 57-104.

Cerrón-PAlomino, Rodolfo. 1976. Diccionario quechua Junin-Huanca. Lima: Instituto de Estudios Peruanos - Ministerio de Educación.

Chávez, Amancio y Gary J. PARKer. 1976. Diccionario quechua Ancash-Huailas. Lima: Instituto de Estudios Peruanos - Ministerio de Educación.

Degregori, CARLOS IVÁN y JURGEN GOLTE. 1973. Dependencia y desestructuración social en la comunidad de Pacaraos. Lima: Instituto de Estudios Peruanos.

FUENZALIDA VOlLmaR, FeRNANDO. 1980 [1965]. "Santiago y el Wamani. Aspectos de un culto pagano en Moyan. Debates en Antropologia 5: 155-187.

GARCÍA MiRANDA, JUAN JOSÉ. 1989. "Los carnavales: ritual y relaciones de intercambio". Antbropologica 7: 55-69.

GONZÁlez Holguín, Diego. 1989 [1608]. Vocabvlario de la lengva general de todo el Perv llamada lengua aqüichua o lengua del Inca.

GutiÉRREZ EstÉVEZ, MANUEL. 1988. "Hipótesis y comentarios sobre la significación de la mama-huaca", en M. Gutiérrez Estévez (comp.), Mito y ritual en América: 286-323. Madrid: Alhambra.

- 1993. "Mayas, españoles, moros y judíos en baile de máscaras. Morfología y retórica de la alteridad", en G. H. Gossen et al. (eds.), De Palabra y Obra en el Nuevo Mundo. La formación del otro. Vol. 3: 323-376. Madrid: Siglo XXI.

MENDIZÁBAL LOSACK, EMILIO. 1964. "Pacaraos: una comunidad en la parte alta del valle de Chancay". Revista del Museo Nacional 33: 12-127.

ORTIZ RESCANIERE, ALEJANDRO. 1973. De Adaneva a Inkarri (una visión indigena del Perí). Lima: Retablo de papel. Instituto Nacional de Investigación y Desarrollo de la Educación. 
- 1980. Huarochiri 400 años después. Lima: Pontificia Universidad Católica del Perú.

- 1986. "Símbolos y ritos andinos: un intento de comparación con el área vecina amazónica.. Anthropologica 3. Lima: 61-86.

- 2001 [1993] La pareja y el mito. Estudio sobre las concepciones de la persona y la pareja en los Andes. Lima: Pontificia Universidad Católica del Perú. 3.. ed. corregida y aumentada.

PÉREZ GALÁN, BEATRIZ. 2001. "Autoridades étnicas y territorio. El ritual del "linderaje" en una comunidad andina". Anthropologica 19: 365-382.

Platt, Tristan. 1980. "Espejos y maíz: el concepto de yanantin entre los macha de Bolivia", en E. Mayer y R. Bolton (eds.), Parentesco y matrimonio en los Andes: 139-182. Lima: Pontificia Universidad Católica del Perú.

Quesada, FÉlIX. 1976. Diccionario quechua Cajamarca-Cañaris. Lima: Instituto de Estudios Peruanos - Ministerio de educación.

QUISPE, UlPIANO. 1969. La herranza de Choque Huarcaya y Huancasancos, Ayacucho. Lima: Instituto Indigenista Peruano.

RIVERA ANDÍA, JUAN JAVIER. 2000a. Arrebatar y fecundar: aproximaciones a los significados y concepciones en torno a los ritos de marcación del ganado en una comunidad campesina de la cuenca alta del río Chancay. Tesis (Lic.) Pontificia Universidad Católica del Perú. Facultad de Ciencias Sociales.

- 2000b. "Los gentiles de Llampa". Anthropologica 18: 271-280.

- 2003. La fiesta del ganado en el valle de Chancay (1962-2002). Religión y ritual en los Andes: etnografía, documentos inéditos e interpretación. Lima: Pontificia Universidad Católica del Perú.

SOUFFEZ, MARIE-FRANCE. 1992. "La racraica o aracrayca ". Anthropologica 10: 251-274

WaChTEl, NATHAN. 1997 [1992]. Dioses y vampiros. Regreso a Chipaya. México: Fondo de Cultura Económica. 